\title{
VALORACIÓN ECONÓMICA DEL SUELO Y GESTIÓN AMBIENTAL: APLICACIÓN EN EMPRESAS FLORICULTORAS COLOMBIANAS*
}

\author{
SANDRA MILENA SILVA ARROYAVE" \& FRANCISCO CORREA RESTREPO \\ UNIVERSIDAD DE MEDELLÍN - UNIVERSIDAD DE ANTIOQUIA
}

Recibido/Received/Recebido: 09/11/2009 - Aceptado/ Accepted/Aprovado: 12/04/2010

\begin{abstract}
Resumen
Este artículo tiene como objetivo central presentar la valoración económica de bienes y servicios ambientales brindados por el recurso suelo vinculado a empresas floricultoras, la cual se plantea como criterio base para establecer una subvención ambiental como mecanismo de fortalecimiento de la gestión ambiental empresarial en Colombia. Así, mediante una revisión bibliográfica analítica, se realiza un reconocimiento de la normativa ambiental nacional en torno al control de la contaminación del suelo. Igualmente, se aplica el método de transferencia de beneficios como mecanismo de valoración económica y se propone un modelo de gestión ambiental en empresas floricultoras colombianas a través de la subvención ambiental. Este trabajo concluye que la información asociada al valor económico de los bienes y servicios ambientales de un recurso natural es relevante porque permite dar una idea de la importancia de los mismos, al tiempo que es fundamental en el establecimiento de la tarifa mínima requerida en el instrumento económico.
\end{abstract}

Palabras clave: Valoración económica, bienes y servicios ambientales, subvención, gestión ambiental.

\section{ECONOMIC VALUATION OF SOIL AND ENVIRONMENTAL MANAGEMENT: IMPLEMENTATION IN COLOMBIAN FLOWER ENTERPRISES}

\begin{abstract}
This paper presents the economic valuation of environmental goods and services provided by soil associated to flower enterprises as a fundamental criterion to establish an environmental subvention to strengthen enterprise environmental management in Colombia. An acknowledgment of national environmental normative is made through an analytic bibliographic review in relation to soil contamination control. Also, transference method of benefits is applied as economic valuation mechanism and a model of environmental management model is proposed in Colombian flower enterprises through environmental subvention. This paper concludes that information associated to environmental goods and services economic value of a natural resource is relevant because it
\end{abstract}

Artículo generado a partir del proyecto de investigación titulado "Los instrumentos económicos como incentivos a la internalización de costos ambientales en empresas floricultoras colombianas", realizado por la primera autora como requisito para optar al título de Magíster en Administración - MBA, de la Universidad de Medellín, Colombia. Financiado por la Universidad de Medellín.

Ingeniera Ambiental, Universidad de Medellín, Colombia. Estudiante Maestría en Administración-MBA, Universidad de Medellín, Colombia. Docente Gestión Ambiental, Fundación Universitaria María Cano, Medellín, Colombia. Participación en proyectos de investigación con el Grupo de Investigaciones y Mediciones Ambientales (GEMA, categoría C de Colciencias) y Grupo de Economía Aplicada (GEA, categoría B de Colciencias), de la Universidad de Medellín, Colombia. Correo electrónico: smsilva@udem.edu.co.

- Economista y especialista en Evaluación Socioeconómica de Proyectos, Universidad de Antioquia, Medellín, Colombia. Magíster en Ciencias Económicas, Área de Economía de la Energía y los Recursos Naturales, Universidad Nacional de Colombia. Profesor asociado, coordinador del Grupo de Economía Aplicada (GEA) de la Universidad de Medellín, Colombia. Correo electrónico: fcorrea@ udem.edu.co. 
allows providing an idea of their importance, at the same time, it is fundamental in the establishment of the minimum required tariff in the economic instrument.

Keywords: Economic valuation, goods and environmental services, subsidy, environmental management.

\title{
VALORIZAÇÃO ECONÔMICA DO SOL E ADMINISTRAÇÃO AMBIENTAL: APLICAÇÕES EM FIRMAS FLORICULTORAS COLOMBIANAS
}

\begin{abstract}
Resumo
Este artigo discute a valorização econômica de bens e serviços ambientais fornecidos pelo recurso do solo, relacionados as firmas floricultoras, como critério para o estabelecimento de um subsídio para fortalecer a gestão ambiental do empresariado na Colômbia. A base de uma revisão da literatura analítica, nós realizamos um levantamento sobre a legislação ambiental nacional em quanto ao controle da contaminação do solo. Aplica-se o método de transferência de benefícios, como um mecanismo de avaliação econômica e propõe-se um modelo de gestão ambiental em empresas de flores da Colômbia mediante um subsídio ambiental. O documento conclui que a informação associada com o valor econômico de bens e serviços ambientais de um recurso natural é essencial porque da uma idéia de sua importância. Além disso, é fundamental para estabelecer a taxa mínima exigida pelo instrumento econômica.
\end{abstract}

Palavras chave: Valorização econômica, bens e serviços ambientais, subvenção, administração ambiental.

Silva, S. \& Correa, F. (2010) Valoración económica del suelo y gestión ambiental: aplicación en empresas floricultoras colombianas En: Revista de la Facultad de Ciencias Económicas de la Universidad Militar Nueva Granada. rev.fac.cienc.econ, XVIII (1)

JEL: XXXXX

\section{Introducción}

Los recursos naturales son todos los factores de la naturaleza que el hombre puede utilizar con el fin de satisfacer sus necesidades, se brindan en forma espontánea y se caracterizan por poseer una gran riqueza energética, diversidad de especies animales y vegetales. El aire, el petróleo, los minerales, los vegetales, los animales, etc., son ejemplos de los recursos naturales que el hombre puede utilizar. Específicamente, puede decirse que el suelo es un componente esencial del ambiente en el que se desarrolla la vida; es frágil, de difícil y larga recuperación (tarda desde miles a cientos de miles de años en formarse), y de extensión limitada, por lo que se considera como recurso no renovable. Se usa para fines muy diversos: agricultura, ganadería, pastos y montes, extracción de minerales y de materiales para la construcción, soporte para las edificaciones, eliminación de residuos; para actividades de ocio y recreo (Dorronsoro, 2007).

El suelo provee importantes bienes y servicios ambientales, dentro de los cuales se destaca ser el sustento de alimento para las plantas, almacenar nutrientes; poseer y albergar materia orgánica proveniente de restos de animales y vegetales; ser el hábitat de diversos organismos que transforman la materia orgánica presente en él; entre otros factores que lo hacen ser esencial en el desarrollo de los ecosistemas de los cuales forma parte. Ahora, dentro de los contaminantes con gran impacto sobre el suelo están los plaguicidas, sustancias formadas por compuestos tóxicos que se han introducido deliberadamente en el medio ambiente para combatir plagas y enfermedades de las plantas; pueden acumularse 
en el suelo o bien filtrarse en las aguas subterráneas o evaporarse y posteriormente volver a depositarse en el suelo. Así mismo, pueden afectar la biodiversidad de este recurso debido a su escasa selectividad, $e$ incorporarse en la cadena trófica, situación que puede generar la pérdida irrecuperable de los bienes y servicios brindados por dicho recurso.

Así pues, teniendo en cuenta la estrecha relación existente entre los recursos naturales, las organizaciones y el ser humano, surge la necesidad de crear regulaciones ambientales que protejan y propendan por un uso adecuado de estos recursos, pues a partir de ellos, se satisfacen las necesidades vitales de la población mundial. En consecuencia, en países como Colombia surgen regulaciones ambientales como el Decreto Ley 2811 de 1974 y la Ley 99 de $1993^{1}$, a partir de las cuales se logra incluir la variable ambiental como un factor preponderante en la supervivencia de la población, puesto que a través de los recursos del medio, se obtienen las materias primas e insumos requeridos en los procesos productivos de las organizaciones, concebidas como fuentes fundamentales para la generación de satisfactores sociales. No obstante, la legislación colombiana aún no ha estipulado la regulación para cada recurso como tal, en este sentido, sólo se cuenta con un conjunto de estatutos que han tenido como objetivo fundamental el aprovechamiento adecuado del recurso hídrico y del aire. En cuanto al suelo, la normativa existente es muy limitada.

De esta manera, es importante resaltar la necesidad de crear políticas públicas y estrategias de regulación, que permitan disminuir el impacto ambiental negativo que se produce sobre el suelo (consecuencia de diversas actividades que se realizan en los procesos productivos de la industria y demás sectores económicos), y generar una conciencia sobre la importancia de conservar los recursos naturales presentes en el medio. Ahora, una estrategia para regular permanentemente las actividades económicas de las empresas, en cuanto a la generación de impactos ambientales negativos sobre el suelo, es el uso de instrumentos económicos que puedan incentivar a los agentes productivos para que inviertan en la protección y conservación de los recursos naturales.

En consecuencia, este artículo tiene como objetivo evidenciar la importancia económica de los bienes y servicios ambientales brindados por el recurso suelo en la creación de una subvención ambiental que promueva la inserción de una adecuada gestión ambiental en empresas floricultoras colombianas. En ese sentido, la primera sección de éste artículo presenta la problemática asociada al uso económico del recurso suelo. Por su parte, la segunda sección establece la valoración económica de bienes y servicios brindados por el suelo. Seguidamente, en la tercera sección, se presenta el diseño de una subvención ambiental como mecanismo de fortalecimiento de la gestión ambiental en empresas floricultoras colombianas. Adicionalmente, se presentan conclusiones sobre el tema de estudio.

\section{La problemática en el uso económico del recurso suelo}

El sistema económico y productivo que hace parte del mundo organizacional no es cerrado y tampoco auto-sostenido, pues existe una continua influencia recíproca entre el proceso económico y el medio ambiente en busca de índices crecientes de bienestar para las comunidades. Esto significa, que las organizaciones reciben recursos naturales valiosos y generan desperdicios que pueden o no estar sujetos a costos para su tratamiento y disposición. De lo anterior se desprende que todo proceso de producción-consumo, toma recursos del medio natural, los aprovecha y finalmente arroja desperdicios, que si superan la capacidad de carga del ambiente, terminan necesariamente por degradarlo (Miranda, 2001).

El Decreto 2811 de 1974 contiene el Código Nacional de Recursos Naturales Renovables y de Protección al Medio Ambiente. Por medio de la Ley 99 de 1993, se crea el Ministerio del Medio Ambiente, se reordena el Sector Público encargado de la gestión y conservación del medio ambiente y los recursos naturales renovables, se organiza el Sistema Nacional Ambiental, SINA y se dictan otras disposiciones. 
En este sentido, se resalta el hecho de que aunque las actividades económicas, especialmente la agricultura, vienen sustituyendo el uso de sustancias como plaguicidas y fertilizantes por otras menos contaminantes, el ritmo de sustitución está por debajo del crecimiento agrícola, por lo cual se presenta un des-balance que genera un uso intensivo del recurso suelo por parte de las sustancias químicas mencionadas. Igualmente, otras actividades productivas también realizan un uso intensivo de este recurso, situación que está conduciendo a una degradación creciente del suelo, así como a una pérdida irrecuperable del mismo. El uso inadecuado de este recurso trae como consecuencia la imposibilidad de hacer un uso óptimo del suelo en la agricultura, la ganadería, la recreación, etc., dado que éste recurso provee importantes funciones ambientales, dentro de las cuales se destaca ser el sustento de alimento para las plantas, almacenar nutrientes, poseer y albergar materia orgánica proveniente de restos de animales y vegetales, ser el hábitat de diversos organismos que transforman la materia orgánica presente en él, entre otros factores que lo hacen ser esencial en el desarrollo de los ecosistemas de los cuales forma parte.

Adicionalmente, puede decirse también que en el caso colombiano, no existen normas técnicas con valores límites permisibles asociados al recurso suelo, pues los parámetros tenidos en cuenta por el gobierno nacional consideran en primera instancia los recursos agua y aire, dejando por último la creación de instrumentos que regulen el uso y aprovechamiento del suelo como recurso fundamental para el desarrollo de actividades productivas. Es importante resaltar que las aproximaciones existentes en esta temática se refieren, en general, a la disposición final de residuos sólidos en el suelo y no a la contaminación que pueda generase en él, de forma directa a través del uso de sustancias como los plaguicidas. De esta manera, se establece que una forma de controlar la generación de impactos ambientales negativos en el suelo es a través de la creación de instrumentos económicos que permitan fortalecer la gestión ambiental organizacional. A continuación se presentan entonces algunos referentes legislativos asociados al manejo del recurso suelo.

\subsection{Normativa ambiental enmarcada en el recurso suelo}

La Constitución de 1991 destinó sus primeros 10 artículos para enunciar aquellos que habría de considerar los primeros orientadores del Estado Colombiano y en su artículo 8 estatuyó la protección de las riquezas naturales de la Nación como principio guía de la actuación del Estado y los particulares: "Es obligación del Estado y de las personas proteger las riquezas culturales y naturales de la Nación". No se trata de una simple declaración constitucional o de un enunciado retórico. El articulo 8 al erigirse como principio se dimensiona como un verdadero instrumento conductor de la política estatal y como punto obligado de referencia para evaluar la actuación del Estado y los particulares, produciendo desde luego consecuencias jurídicas concretas.

El deber de protección del ambiente a cargo del Estado se encuentra reforzado en el artículo 79 cuyo texto indica que "Es deber del Estado proteger la diversidad e integridad del ambiente" y "conservar las áreas de especial importancia ecológica... ", por su parte el articulo 80 agrega el deber de prevenir y controlar los factores de deterioro ambiental, imponer las sanciones legales y exigir la refacción de los daños causados. Además, la Constitución política hace mención también al deber de protección del Estado y a la cooperación que a de prestar a otras naciones para la protección de los ecosistemas situados en las zonas fronterizas. La obligación Estatal en materia ambiental es tal, que la propia carta política le proporciona al Presidente de la República una herramienta excepcional para injuriar hechos que amenacen perturbar en forma grave el orden ecológico del país (Sanclemente, 2000).

Así mismo, como una forma más de garantizar esa protección ecológica, el artículo 361 establece la creación del Fondo Nacional de Regalías, cuyos recursos deberán ser obligatoriamente destinados, entre otras, a la preservación del medio ambiente. Preceptúa el artículo 361: "Con los ingresos provenientes de las regalías que no sean asignados a los departamentos y municipios, se creará un Fondo Nacional de Regalías cuyos recursos se destina- 
rán a las entidades territoriales en los términos que señale la ley. Estos fondos se aplicarán a la promoción de la minería, a la preservación del ambiente y a financiar proyectos regionales de inversión definidos como prioritarios en los planes de desarrollo de las respectivas entidades territoriales" (Constitución Política de Colombia, 1991).

Igualmente, en materia legislativa, Montes \& García (2005) hacen un recuento de la normativa ambiental existente en Colombia enfocado al tema específico de los plaguicidas, en donde se plantea que el Código Nacional de Recursos Naturales Renovables y de Protección al Medio Ambiente, Decreto 2811 de 1974, establece que para prevenir el deterioro ambiental y los daños a la salud humana, se deben establecer requisitos y condiciones para la importación, fabricación, transporte, comercialización, manejo y disposición de sustancias y productos tóxicos o peligrosos; disposición que ha sido soporte de la normativa sobre plaguicidas y mercancías peligrosas.

Ahora, el Código Sanitario Nacional, Ley 9a de $^{\text {a }}$ 1979, desarrolla múltiples temas entre los cuales se destacan los residuos sólidos, emisiones atmosféricas, sustancias químicas, sustancias peligrosas, sustancias toxicas, plaguicidas, etc. En relación con los plaguicidas, esta Ley dedica sus artículos 136 a 144 a regular lo relativo a su transporte, almacenamiento, uso, comercio y distribución, estableciendo normas para la salvaguarda de la salud y la seguridad de las personas. Igualmente, establece la obligación de expedir registro en los casos de importación, fabricación o comercio de cualquier tipo de plaguicidas, consagrando obligaciones de tipo sanitario para los fabricantes, formuladores, envasadores o manipuladores de este tipo de sustancias. Por su parte, el Decreto 1843 de 1991 reglamenta el uso y manejo de plaguicidas y es básico en la legislación colombiana sobre el tema. A lo largo de este decreto se abarcan temas relacionados con las funciones de la administración pública en materia de plaguicidas, se fijan parámetros técnicos sobre los niveles de toxicidad, requisitos sobre experimentación con plaguicidas, licencias para producción, proceso y formulación de estas sustancias, etc. El objeto de este reglamento es evitar que el uso y manejo de plaguicidas afecte la salud de la comunidad, la sanidad animal y vegetal o causen deterioro al ambiente. Crea el Consejo Nacional de Plaguicidas y los Consejos Seccionales de Plaguicidas, que tienen carácter consultivo y asesor de los Ministerios de Salud y de Agricultura y de las direcciones seccionales de salud y agricultura respectivamente y el Consejo Intrasectorial Nacional que tiene carácter de asesoría técnica permanente del sistema de salud y cuya secretaria está a cargo de la división de sustancias potencialmente toxicas.

Este Decreto, restringe de manera general todos aquellos productos plaguicidas o sus componentes, en los cuales se observen o se demuestren efectos cancerígenos, mutagénicos o teratogénicos ocasionados en dos o más especies animales con metabolismo similar al de los mamíferos; que su uso y manejo constituyan grave riesgo para la salud de las personas, de la sanidad animal y vegetal o la conservación del ambiente, según lo determinen los Ministerios de Salud y/o Agricultura, o que no haya demostrado efectividad o eficacia para el uso que se propone. En lo relativo a los desechos y los residuos de plaguicidas, establece que la persona natural o jurídica que los maneja debe dar tratamiento previo a su evacuación final, de manera que los efluentes no sobrepasen los límites permitidos oficialmente. Adicionalmente, para el tema de los residuos de plaguicidas la norma aplicable es el Decreto 1443 de 2004.

La Ley 99 de 1993, asigna competencias a las autoridades del sector ambiental y determina entre las funciones del Ministerio del Medio Ambiente la obligación de establecer los límites máximos permisibles de emisión, descarga, transporte o deposito de sustancias, productos, compuestos o cualquier otra materia que pueda afectar el medio ambiente o los recursos naturales, obligación que también se le impone a las corporaciones autónomas regionales. Del mismo modo, el Ministerio debe expedir las regulaciones ambientales para la distribución y uso de sustancias químicas utilizadas en actividades agropecuarias y dictar regulaciones para impedir la fabricación, importación, posición y uso de armas 
químicas, biológicas y nucleares, así como la introducción al territorio nacional de residuos nucleares y desechos tóxicos o subproductos de los mismos. Esta Ley también fija las competencias de los grandes centros urbanos, establece que los municipios, distritos o aéreas metropolitanas tienen la responsabilidad de ejecutar el control de vertimientos y emisiones contaminantes, disposición de desechos sólidos y de residuos tóxicos y peligrosos.

Según esta Ley, el Ministerio de Ambiente otorga de manera privativa la licencia ambiental para la producción e importación de pesticidas, y de aquellas sustancias, materiales o productos sujetos a controles por virtud de tratados, convenios y protocolos internacionales. Esta reglamentación se dirige a todas aquellas personas naturales o jurídicas, públicas o privadas, que fabriquen, formulen, importen, envasen, distribuyan, comercialicen, empaquen, almacenen y transporten plaguicidas, así como al consumidor o usuario final de los mismos, y a las personas que generen y manejen residuos o desechos peligrosos provenientes de plaguicidas. Finalmente, la Ley establece funciones de control y vigilancia de las autoridades ambientales y sanciones en caso de violación de estas normas.

Continuando con la normatividad aplicable a los plaguicidas, es importante anotar que el Decreto 1220 de 2005, reglamentario de la Ley 99 de 1993 en cuanto a licencias ambientales dispone que requerirán de licencia ambiental la importación y producción de pesticidas y de aquellas sustancias, materiales o productos sujetos a controles por virtud de tratados, convenios y protocolos internacionales, determinando que la mencionada importación deberá ajustarse al procedimiento señalado en la Decisión Andina 436 del Acuerdo de Cartagena y sus normas reglamentarias; para los cuales da competencia privativa al Ministerio de Ambiente, Vivienda y Desarrollo Territorial. Las corporaciones autónomas regionales, las de desarrollo sostenible, los grandes centros urbanos y las autoridades ambientales creadas mediante la Ley 768 de 2002, son competentes para el otorgamiento de la licencia ambiental para los proyectos cuyo objeto sea el almacenamiento de sustancias peligrosas, como son los plaguicidas.
La normatividad expedida por la cartera de agricultura, hace referencia a la prohibición de venta y uso de ciertos plaguicidas únicamente con destino a determinados cultivos. En este orden de ideas, la Resolución 447 de 1974 prohíbe el uso y venta de insecticidas clorados con destino al cultivo del tabaco (Aldrin, Clordano, DDD, Dieldrin, Endrin, Isobenzán, Melipax y Toxapheno) y la Resolución 209 de 1978 prohíbe el uso de plaguicidas organoclorados en el cultivo del cafeto (DIH, Lindano, cetonas policíclicas, policlorados y los fenoxiderivados), entre otras resoluciones.

Otro tema de interés fundamental en el uso de plaguicidas a nivel nacional es la existencia de exenciones tributarias a los plaguicidas. Sin lugar a dudas, la normatividad tributaria favorece el uso de agroquímicos, toda vez que el artículo 424 del Estatuto Tributario excluye expresamente del impuesto sobre las ventas a los abonos minerales o químicos nitrogenados, los abonos minerales o químicos fosfatados, los abonos minerales o químicos potásicos, los plaguicidas e insecticidas y las materias primas químicas con destino a la producción de plaguicidas e insecticidas y de los fertilizantes (exactamente para la producción de los abonos anteriormente mencionados), es decir que la venta o la importación de los anteriores bienes no causa el impuesto sobre las ventas). El Decreto 358 de 2002 establece los requisitos que se deben cumplir para que la venta o la importación de los plaguicidas o sus materias primas este excluida del impuesto sobre las ventas. En cuanto al impuesto sobre la renta, dispone el estatuto tributario que, no constituirán renta ni ganancia ocasional para el beneficiario, los ingresos constitutivos por los contribuyentes por concepto de indemnizaciones o compensaciones recibidas por concepto de la erradicación o renovación de los cultivos, o por concepto del control de plagas, cuando esta forme parte de programas encaminados a racionalizar o proteger la producción agrícola nacional y dichos pagos se efectúen con recursos de origen público, sean estos fiscales o parafiscales (Montes \& García, 2005).

En consecuencia, puede decirse que en Colombia, es necesario crear políticas, estrategias instituciona- 
les, estrategias de regulación, metas corporativas, las cuales permitan disminuir el impacto ambiental negativo que se produce sobre el suelo (consecuencia de diversas actividades que se desempeñan en los procesos productivos de la industria y demás sectores económicos), y generar una conciencia sobre la importancia de conservar y preservar ${ }^{2}$ los recursos naturales presentes en el medio.

Específicamente, una estrategia para regular permanentemente la gestión realizada por las empresas colombianas en cuanto a la generación de impactos ambientales negativos en el suelo, es por medio de instrumentos económicos que puedan incentivar a las organizaciones para que inviertan en la protección y conservación de los recursos naturales. En este sentido, se plantea entonces que los instrumentos económicos son herramientas eficientes y eficaces para el control y la posible prevención de fenómenos de contaminación, en tanto permiten generar acciones costo efectivas y presentan una mayor flexibilidad que las herramientas de comando y control, pues posibilita generar desarrollo al tiempo que se promueven prácticas amigables con el medio ambiente como la compra de tecnologías limpias y la incorporación de buenas prácticas ambientales dentro de una organización. En este orden de ideas, es fundamental resaltar que la valoración de los bienes y servicios ambientales brindados por un recurso natural como el suelo es un elemento clave en la creación de los instrumentos económicos, pues a través de ella, puede reconocerse la relevancia económica de proteger dichos bienes y servicios y evitar así su posible pérdida. A continuación se establece entonces una aproximación a la valoración económica de bienes y servicios brindados por el recurso suelo.

\section{Valoración económica de servicios ambientales en empresas floricultoras}

La normativa de los recursos naturales está directamente vinculada con el reconocimiento de la impor- tancia que generan estos recursos para el ser humano y para el desarrollo de la vida en la tierra. En este sentido, se considera que una forma de demostrar esta importancia es a través de la valoración económica de los mismos, pues estas aproximaciones dan una idea general del valor económico y social del recurso y de lo que significaría su pérdida o deterioro para las actividades cotidianas del ser humano.

De esta manera, este artículo presenta la valoración económica de servicios ambientales asociados al suelo empleado en actividades de floricultura de una unidad productiva de análisis ubicada en el Oriente Antioqueño, para lo cual se emplea el método de transferencia de beneficios, el cual se define como la transferencia de valores económicos estimados existentes en un contexto o sitio de estudio para estimar valores económicos en otro diferente (sitio de política). Así, este método tiene como base fundamental el uso de valores económicos obtenidos en estudios previos, para estimar, mediante su transferencia, el valor económico de los cambios en ecosistemas naturales específicos (Correa, 1999).

La elección de este método radica fundamentalmente en su facilidad de aplicación y en el hecho de que no incurre en costos elevados de aplicación como las metodologías de valoración contingente, el costo de viaje y el método de los precios hedónicos, puesto que como ya se mencionó anteriormente, una de sus virtudes es que se trata de una técnica que se basa en estimaciones obtenidas en estudios ya realizados. Así, se plantea que frecuentemente las agencias gubernamentales y las organizaciones privadas tienen la necesidad de establecer estimaciones del valor económico de los servicios ambientales para realizar análisis de costo-beneficio, evaluación de daños a recursos naturales o para facilitar las decisiones de política y gestión en general. Sin embargo, en muchas situaciones no es práctico para una institución u organización recolectar información primaria sobre la cual basar las estimaciones de valoración. Por lo tanto, la aplicación de los resultados

2 Conservar se define como "la utilización humana de la biosfera para que rinda el máximo beneficio sostenible, a la vez que mantiene el potencial necesario para las aspiraciones de futuras generaciones. Preservar se entiende como "la mantención del estado natural original de determinados componentes ambientales, o de lo que reste de dicho estado, mediante la limitación de la intervención humana en ellos al nivel mínimo, compatible con la consecución de dicho objetivo" (DRAL, 2005). 
previos de otras investigaciones en situaciones similares es una alternativa muy atractiva con respecto a hacer una nueva investigación que implica tiempo y dinero. No obstante, es importante aclarar que los valores obtenidos por este método son sólo indicadores de magnitud de importancia que orientan la toma de decisiones, más no valores para establecer pagos por servicios ambientales estrictamente $e^{3}$.

En este orden de ideas, puede decirse que éste método emplea valores monetarios de bienes ambientales estimados en un contexto determinado, para valorar los beneficios de un bien similar bajo distinto contexto, del cual se desconoce su valor (Osorio, 2006). Existen tres formas de realizar la transferencia de valores: 1) transferencia de puntos estimados o valores fijos, 2) transferencia de medidas de tendencia central y, 3) transferencia de estimaciones de valores administrativamente aprobadas (juicio de especialistas). En el primer caso, los beneficios totales del sitio objeto de análisis donde se va a establecer la política se estiman tomando los valores por unidad estándar provenientes de los datos de un sitio de estudio ${ }^{4}$. Por su parte, en la transferencia de medias de tendencia central se calcula el valor promedio $\mathrm{u}$ otra medida de tendencia central para los puntos a estimar. Este valor promedio debe ser calculado a partir de las estimaciones mejor ajustadas obtenidas de los diversos estudios analizados. Finalmente, en el tercera forma, beneficios totales de el sitio donde se va a establecer la política se estiman tomando los valores por unidad provenientes de un juicio de un especialista o de un proceso de opinión ${ }^{5}$.

Ahora, en este estudio se empleará el método de transferencia a través de valores fijos o puntos estimados, el cual según Rosenberger \& Loomis (2003, citado por Osorio, 2006) tiene el siguiente procedimiento metodológico:

a) Definir el sitio de análisis (sitio de política). Esta definición debe incluir las diversas características del sitio a analizar y definir cuál es la información que se necesita y en qué unidades.

b) Localizar y recoger resultados de investigaciones originales. Se debe realizar una cuidadosa revisión de literatura y obtener copias de potenciales publicaciones relevantes.

c) Revisar cuidadosamente los estudios relevantes, analizando si el contexto de la investigación original se aproxima al del sitio de política, además si los valores estimados están en las unidades adecuadas. Por último, se debe revisar la calidad de la investigación.

d) Seleccionar un punto estimado o un rango de puntos estimados. Este punto o rango estimado debe tener el mejor ajuste de los posibles candidatos.

e) Transferir el punto estimado o el rango de puntos estimados al sitio de política. Para agregar el punto estimado al contexto del sitio de política se multiplica el valor por el total del número de unidades logrando de esta manera una estimación del valor total para el bien o servicio ambiental en el sitio de política.

\subsection{Aplicación de transferencia de beneficios en una empresa floricultora colombiana}

La adopción de esta metodología en la zona de estudio implica la definición de las características físicas del terreno, la identificación de los servicios ambientales potenciales ofrecidos por el recurso suelo y la transferencia de los valores monetarios.

3 Las organizaciones deben tener en cuenta que la transferencia de beneficios comporta riesgos importantes de obtener resultados sesgados. Este caso se puede dar, por ejemplo, cuando el bien ya estudiado difiere notablemente del bien al que se quieren extrapolar las estimaciones, tanto en los impactos físicos como en la población afectada. En el caso analizado en este trabajo sólo se quiere dar cuenta de la importancia económica del recurso suelo y, dado el enfoque de valoración preliminar y la limitación de recursos y tiempo, se optó por aplicar el método de transferencia de beneficios.

4 Por ejemplo, los beneficios totales de pescar en un sitio donde se va a establecer una política pueden estimarse por el producto, de algún valor estándar por día de pesca establecido en un sitio de estudio (un estudio ya realizado de un sitio con similares características al sitio analizado) y el total los días de pesca en el sitio de la política.

5 Por ejemplo, los beneficios totales del sito donde se va implementar la política pueden ser estimados por el producto de la opinión especializada sobre el valor ajustado por el día de pesca en un sitio de estudio y el total de días de pesca del sitio de la política. 


\subsubsection{Características físicas del terreno de estudio}

La zona de estudio se encuentra a una altura aproximada de 2.130 msnm y su temperatura promedio es de $18^{\circ} \mathrm{C}$, lo cual sugiere una clasificación de zona de vida según Holdrige (1967) correspondiente a Bosque Húmedo Montano Bajo (bh - MB), piso climático frío (Cornare, 2005). Los suelos son moderadamente inclinados $\mathrm{u}$ ondulados con pendientes inferiores al 12\%; con una retención de humedad muy alta o mediana, permeabilidad lenta y nivel de fertilidad moderada, hay algunos cultivos transitorios y permanentes.

Los usos del suelo de la zona de estudio hacen referencia a Cultivos Transitorios Confinados Floricultura (Cornare, 2005), de tal manera que el bioma identificado para este lugar según la clasificación de Costanza et al. (1997) ${ }^{6}$ puede referirse a Tierra de cultivos y Bosques plantados.

\subsubsection{Identificación de servicios ambientales potenciales de la zona de estudio}

Como se mencionó anteriormente, al analizar las características de la zona de estudio se identificó la existencia potencial de dos ecosistemas, los cuales corresponden a bosque plantado y tierras de cultivo. Esto significa que si en algún momento el uso del suelo de la zona de estudio deja de ser floricultura, este terreno podría convertirse en los ecosistemas enunciados.

En este sentido se determinó, a partir de Costanza et al (1997), los servicios ambientales que prestaría cada ecosistema potencial de la zona de estudio, encontrando:

A partir de esta identificación se establecen entonces los valores en dólares y pesos de cada servicio reportado por Costanza et al (1997) y su valor actualizado a precios del año 2009, al igual que el monto que representarían estos servicios en las 50 Ha de terreno analizado en la zona de estudio (Tabla 2). Debe decirse que Costanza et al (1997) utilizan, igualmente, transferencia de valores fijos, en unos casos, y promedios, en otros, obtenidos de diversos estudios que valoran económicamente los diferentes ecosistemas alrededor del mundo (con métodos directos como la valoración contingente, así como con métodos indirectos cómo el método de costos de viaje, precios hedónicos y costos de reemplazo $)^{7}$.

Adicionalmente, esta valoración se realizó considerando un horizonte de 10 años de sostenimiento de los servicios ambientales mencionados, para lo cual se calculó su valor presente neto, considerando tasas sociales de descuento de $12 \%, 8.95 \%$ y $4.97 \% 8$ (Tabla 3).

Costanza et al (1997) definen qué es función y servicio ecosistémico, y partir de estas definiciones establecen una base conceptual sobre la cual soportan la valoración de los servicios ecosistémicos ofrecidos por los grandes biomas del mundo. Así, definen las funciones ambientales como aquellas que se refieren diversamente al hábitat, a las propiedades biológicas o sistémicas y a los procesos de los ecosistemas. De igual manera, plantea los servicios ecosistémicos como aquellos que representan los beneficios a la población derivados, directa o indirectamente, de las funciones de los ecosistemas. De este modo, agrupa los servicios ecosistémicos en 17 principales categorías y basado en datos de estudios pasados y algunos cálculos propios, determinan el valor en dólares de los servicios ambientales de cada ecosistema.

7 Para algunos estimados de servicios ambientales Costanza et al (1997) convierten el valor estimado en dólares equivalentes utilizando la paridad de poder de compra del PNB per cápita para el país de origen del estudio con respecto al PNB per cápita de Estados Unidos, con el fin de hacer los ajustes por efectos de ingreso. Así mismo, utilizaron valores máximos y mínimos encontrados en la literatura, así como valores promedios con la idea de posibilitar las comparaciones.

8 La tasa de 12\% corresponde a la empleada por el Departamento Nacional de Planeación (DNP) para proyectos públicos; la de $8.95 \%$ se refiere a una economía en crecimiento y la de $4.97 \%$ a la productividad marginal de proyectos en Colombia, estos valores son sugeridos por el estudio de Correa (2006). 
Tabla 1. Servicios ambientales presentes en la zona de estudio ${ }^{9}$

\begin{tabular}{|l|l|}
\hline $\begin{array}{c}\text { Servicios ambientales definidos a partir del uso potencial } \\
\text { en bosque plantado }\end{array}$ & $\begin{array}{c}\text { Servicios ambientales definidos a partir del uso de suelo } \\
\text { como tierra de cultivo }\end{array}$ \\
\hline $\begin{array}{l}\text { - Regulación de agua } \\
\text { - Abastecimiento de agua }\end{array}$ & $\begin{array}{l}\text { - Polinización } \\
\text { - Control de la erosión }\end{array}$ \\
$\begin{array}{l}\text { - Pormación de suelo } \\
\text { - Materias primas }\end{array}$ & \\
\hline - Regulaciónico \\
\hline
\end{tabular}

Tabla 2. Transferencia del valor de los servicios ambientales del año 1997 al año 2009 en dólares y pesos colombianos ${ }^{10}$

\begin{tabular}{|c|c|c|c|c|c|}
\hline Ecosistema & Servicio ambiental & $\begin{array}{l}\text { Valor } 1997 \\
\text { (\$ha/año) }\end{array}$ & $\begin{array}{c}\text { Valor transferido } \\
\text { a } 2009 \\
\text { (US/ha/año) }\end{array}$ & $\begin{array}{l}\text { Valor Total } 2009 \\
\text { (Dólares } 50 \text { ha/ } \\
\text { año) }\end{array}$ & $\begin{array}{l}\text { Valor Total } 2009 \text { (Pesos } \\
\text { colombianos } 50 \text { ha/año) }\end{array}$ \\
\hline \multirow{4}{*}{ Tierra de cultivo } & Polinización & $\$ 14.00$ & $\$ 20.19$ & $\$ 1,009.29$ & $\$ 2,037,688.50$ \\
\hline & Control biológico & $\$ 24.00$ & $\$ 34.60$ & $\$ 1,730.21$ & $\$ 3,493,180.28$ \\
\hline & Producción de alimentos & $\$ 54.00$ & $\$ 77.86$ & $\$ 3,892.98$ & $\$ 7,859,655.63$ \\
\hline & \multicolumn{3}{|l|}{ TOTAL } & $\$ 6,632.49$ & $\$ 13,390,524.40$ \\
\hline \multirow{7}{*}{$\begin{array}{l}\text { Bosque } \\
\text { (plantación) }\end{array}$} & Regulación de agua & $\$ 2.00$ & $\$ 2.88$ & $\$ 144.18$ & $\$ 291,098.36$ \\
\hline & Abastecimiento de agua & $\$ 3.00$ & $\$ 4.33$ & $\$ 216.28$ & $\$ 436,647.53$ \\
\hline & Control de erosión & $\$ 96.00$ & $\$ 138.42$ & $\$ 6,920.85$ & $\$ 13,972,721.11$ \\
\hline & Formación de suelo & $\$ 10.00$ & $\$ 14.42$ & $\$ 720.92$ & $\$ 1,455,491.78$ \\
\hline & Materias primas & $\$ 138.00$ & $\$ 198.97$ & $\$ 9,948.73$ & $\$ 20,085,786.60$ \\
\hline & Regulación del clima & $\$ 141.00$ & $\$ 203.30$ & $\$ 10,165.01$ & $\$ 20,522,434.14$ \\
\hline & \multicolumn{3}{|l|}{ TOTAL } & $\$ 28,115.97$ & $\$ 56,764,179.53$ \\
\hline
\end{tabular}

9 Fuente: Elaboración propia a partir de Costanza et al. (1997).

10 Fuente: Cálculos propios a partir de Costanza et al (1997). El valor total representa el monto de los servicios ambientales en las 50 Ha de terreno de la zona de estudio. Para el cálculo del valor de cada servicio ambiental en pesos colombianos, se consideró una tasa de cambio de 1 USD = 2018.93 pesos, correspondiente a julio de 2009. 
Tabla 3. Valor presente neto de los servicios ambientales por 50 hectáreas, en un período de 10 años, en pesos colombianos $^{11}$

\begin{tabular}{|c|c|c|c|c|}
\hline Ecosistema & Servicio ambiental & VPN $(i=12 \% ; n=10)$ & VPN $(i=8.95 \% ; n=10)$ & VPN $(i=4.97 \% ; n=10)$ \\
\hline \multirow{4}{*}{ Tierra de cultivo } & Polinización & $\$ 26,489,962.25$ & $\$ 30,592,714.81$ & $\$ 37,282,159.08$ \\
\hline & Control biológico & $\$ 45,411,363.86$ & $\$ 52,444,653.96$ & $\$ 63,912,272.70$ \\
\hline & Producción de alimentos & $\$ 102,175,568.69$ & $\$ 118,000,471.42$ & $\$ 143,802,613.58$ \\
\hline & TOTAL & $\$ 174,076,894.81$ & $\$ 201,037,840.20$ & $\$ 244,997,045.36$ \\
\hline \multirow{7}{*}{$\begin{array}{l}\text { Bosque (planta- } \\
\text { ción) }\end{array}$} & Regulación de agua & $\$ 3,784,280.32$ & $\$ 4,370,387.83$ & $\$ 5,326,022.73$ \\
\hline & Abastecimiento de agua & $\$ 5,676,420.48$ & $\$ 6,555,581.75$ & $\$ 7,989,034.09$ \\
\hline & Control de erosión & $\$ 181,645,455.45$ & $\$ 209,778,615.86$ & $\$ 255,649,090.81$ \\
\hline & Formación de suelo & $\$ 18,921,401.61$ & $\$ 21,851,939.15$ & $\$ 26,630,113.63$ \\
\hline & Materias primas & $\$ 261,115,342.21$ & $\$ 301,556,760.30$ & $\$ 367,495,568.04$ \\
\hline & Regulación del clima & $\$ 266,791,762.69$ & $\$ 308,112,342.04$ & $\$ 375,484,602.13$ \\
\hline & TOTAL & $\$ 737,934,662.77$ & $\$ 852,225,626.92$ & $\$ 1,038,574,431.41$ \\
\hline
\end{tabular}

\subsection{Algunas consideraciones sobre la valoración económica obtenida}

A partir de los resultados obtenidos (Tabla 2), puede decirse que el valor de los servicios ambientales de la zona de estudio, como Tierra de cultivo, es de trece millones trescientos noventa mil quinientos veinticuatro $(\$ 13.390 .524,40)$ y cincuenta y seis millones setecientos sesenta y cuatro mil ciento setenta y nueve $(\$ 56.746 .179,53)$ como Bosque. El primer valor mencionado se encuentra asociado a servicios específicos de polinización, control biológico y producción de alimentos; mientras que el segundo, se refiere a regulación de agua, abastecimiento de agua, control de erosión, formación de suelo, materias primas y regulación del clima. Situación que explica el por qué de la diferencia entre ambas valoraciones, pues el ecosistema como Bosque genera a su vez una mayor cantidad de servicios ambientales que la Tierra de cultivos.

Adicionalmente, al considerar la valoración de los servicios ambientales en un período de diez años, es decir, bajo un ecosistema intervenido para producción de alimentos (tierra de cultivo) o para bosque plantado, se establecen algunos planteamientos interesantes en función de la importancia económica de tales ecosistemas. Así, siguiendo los lineamientos de Correa (2006) y Edwards (2002) de utilizar una baja tasa social de descuento $(4.97 \%)^{12}$ cuando se evalúan económicamente servicios ambientales, se tiene que el valor presente neto de los servicios en conjunto del ecosistema Tierra de cultivos en 50 Hectáreas de terreno, genera un valor en pesos

11 Fuente: Cálculos propios.

12 Los respectivos valores para las tasas sociales de descuento de $12 \%$ y $8.95 \%$ son para tierras de cultivo $\$ 82,832,918.34$ y $\$ 94,291,013.51$. Para bosques plantados son $351,139,545.15$ y $399,711,905.09$, respectivamente. Estos valores demuestran que tasas de descuento más altas, implican un mayor castigo para los beneficios de largo plazo. 
colombianos de doscientos cuarenta y cuatro mil millones novecientos noventa y siete mil quinientos cuarenta y cinco $(\$ 244,997,045.36)$. Por su parte 50 hectáreas del ecosistema Bosques, en diez años representaría un valor económico en pesos colombianos de mil treinta y ocho millones quinientos setenta y cuatro mil cuatrocientos treinta y uno (\$1.038.574.431,41) (Tabla 3). La diferencia entre estos valores significa que en un período de diez años, el valor de los servicios ambientales generados por el ecosistema Bosques es 4.2 veces mayor que el valor obtenido por el ecosistema Tierra de cultivos, situación que se presenta por la diferencia en cantidad, diversidad y singularidad de los servicios ambientales que pueden ser generados en cada uno de los ecosistemas analizados.

En este sentido, es vital resaltar que este estudio pretende dar una idea de la importancia económica de mantener las características del suelo de la zona de estudio, como elemento preponderante para su desarrollo, pues en un determinado momento podrían generarse cambios en los usos del suelo que potencien la prestación de más servicios ambientales generados por éste recurso. Ahondando en este último aspecto es importante considerar que de ser factible este proceso de reconversión en usos del suelo, debería realizarse un estudio más detallado, donde se analice la relación costo-beneficio de dicho cambio.

Ahora, es importante resaltar que la información mencionada en este capítulo pretende ser incorporada en el diseño de un instrumento económico que permita una gestión eficaz en el control y la posterior prevención de la contaminación del suelo generada por plaguicidas en zonas floricultoras (como uno de los principales sectores de la economía colombiana que emplea sustancias químicas en la protección de sus cultivos), con el fin de potenciar la prestación de sus diversos servicios ambientales.

\section{Diseño de una subvención como mecanismo de fortalecimiento de la gestión ambiental en empresas floricultoras}

Los instrumentos económicos son una alternativa de gestión ambiental aplicable al caso colombiano, porque apuntan a generar soluciones reales a problemas crecientes que han causado el deterioro ambiental, ya que la flexibilidad que ofrecen permite a los diferentes agentes que intervienen en el proceso, minimizar tanto el costo de cumplir con la regulación, como el costo total en que la sociedad debe incurrir para lograr sus metas de calidad ambiental (García, 2006 y León, 2006). Por tal razón, los instrumentos económicos permiten obtener una solución costo efectiva. Esto significa que este tipo de instrumentos permiten lograr el mismo objetivo de las normas ambientales, reducir la contaminación generada en las actividades productivas; pero a un menor costo que la norma ambiental.

En este sentido, puede decirse que la aplicación de un instrumento económico como la subvención para estimular procesos ambientalmente limpios, puede convertirse en una herramienta eficiente y eficaz en la consecución de los objetivos de una empresa determinada y de la sociedad, los cuales plantean obtener una mayor rentabilidad garantizando una minimización de sus costos, dentro de los que se encuentran todos aquellos aspectos relacionados con la temática ambiental. A continuación, se presenta entonces la propuesta de diseño de la subvención ambiental en una empresa floricultora colombiana.

\subsection{Diseño de la Subvención Ambiental}

La creación de la subvención ambiental tiene como objetivo incentivar la gestión ambiental ${ }^{13} y$ administrativa de organizaciones que promuevan prácticas

13 La gestión Ambiental administrativa se refiere a un conjunto de acciones encaminadas a lograr la máxima racionalidad en el proceso de decisión relativo a la conservación, defensa, protección y mejora del medio ambiente, a partir de un enfoque interdisciplinario y global (Correa, 1999). 
amigables con el medio ambiente. En este sentido, su diseño tuvo en cuenta elementos asociados a la calidad del recurso suelo a partir del uso de sustancias como los plaguicidas, y aspectos de mejoramiento empresarial como la competitividad de una empresa en el mercado. En este último aspecto, Porter \& Van der Linde (1995) (citados por Riera et al, 2005) plantean que, si se aplica correctamente, la política ambiental puede aumentar la productividad y la competitividad de las empresas y, por tanto, de los países. Así, un país podría mejorar su posición en la economía mundial si tuviera una política ambiental más estricta, más acertada pero a la vez más decidida tanto en la aplicación de premios (subsidios) y castigos (impuestos) (Riera et al, 2005). En este sentido, Porter y Van der Linde (1995) establecen que las regulaciones pueden impulsar las innovaciones de dos formas. Por un lado, las empresas pueden mejorar la forma en que gestionan sus problemas de contaminación, pues las tecnologías que lleguen a adoptar pueden reducir sus costos. Por otro lado, las innovaciones pueden mejorar tanto los productos de las empresas como el propio proceso de producción.

Así, el proceso de creación de la subvención, se enmarca en la definición de criterios como: 1) las características del plaguicida, 2) la gestión ambiental empresarial, 3) la relación empresa-mercado y, 4) el monitoreo de la calidad del suelo. Estos son los elementos representativos del enfoque ambiental y administrativo del instrumento económico que se propone en este estudio. Posteriormente, se definen los pesos de ponderación para cada criterio y se establece la fórmula para el cálculo, considerando, la determinación de elementos de apoyo como la tarifa mínima y el fondo ambiental que subsidiará la subvención. A continuación se enuncian los elementos mencionados.

\subsubsection{Características del plaguicida}

Los plaguicidas son sustancias que poseen diversas propiedades como: clasificación según el elemento químico que los conforma; estado físico; toxicidad, persistencia; bioacumulación; solubilidad, entre otros aspectos que los hacen específicos para diferentes tipos de plagas y cultivos. Así, para el análisis de la contaminación del suelo, se seleccionaron factores como la persistencia y la toxicidad puesto que ambos elementos permiten determinar el grado de afectación de este recurso. Por tal razón, éste criterio será entendido como el grado de toxicidad y persistencia, donde el primer elemento se refiere a la capacidad o la propiedad de una sustancia de causar efectos adversos sobre la salud, tanto de personas, como de animales, vegetales, microorganismos, entre otros. Su medición se representa en clase I: altamente tóxico (0); clase II: moderadamente tóxico $(0,33)$; clase III: bajamente tóxico $(0,66)$ y clase IV: no tóxico $(1)$ (EPA, 2009).

Con respecto a la persistencia, puede decirse que ésta se define como el tiempo de vida media de una sustancia, esto indica el tiempo necesario para que la mitad del residuo desaparezca bajo condiciones normales. Su duración se expresa, según la Universidad de Hertfordshire (2005) en: menos de 30 días, no persistente (1); entre 30 y 100 días, moderadamente persistente (0.66); entre 100 y 365 , persistente $(0,33)$ y mayor a 365 , muy persistente (0).

\subsubsection{Gestión ambiental empresarial}

Teniendo en cuenta que la gestión ambiental puede considerarse como un conjunto de acciones encaminadas a lograr la máxima racionalidad en el proceso de decisión relativo a la conservación, defensa, protección y mejora del medio ambiente, a partir

14 Flor Verde es un programa que certificado por el Icontec que tiene como objetivos la adopción de las buenas prácticas agrícolas, la minimización del uso de agroquímicos, la protección de los derechos fundamentales de los trabajadores, la calidad del producto y la responsabilidad gerencial. Los sellos verdes a su vez, son mecanismo para certificar a las empresas en general o sus productos como productos ambientalmente limpios y de bajo impacto ambiental. 
de un enfoque interdisciplinario y global llevado a cabo por personas, empresas, organizaciones o instituciones; se determinó que este criterio abarcaría todos aquellos aspectos relacionados con:

- La adopción de programas ambientales como flor verde y/o sellos verdes, también llamados ecoetiquetas ${ }^{14}$. Estos programas representan la adopción de buenas prácticas dentro de una empresa donde además de lograr un desempeño ambiental, se favorece la articulación de las características sociales y económicas que rodean la producción. Su medición se representa con uno (1) cuando exista dicho programa o cero (0) en el caso contrario y se determina a partir del certificado expedido por el Icontec, Cornare o alguna institución u ONG que sea reconocida en el ámbito mundial y otorgue este tipo de sellos.

- El uso de plaguicidas y su relación con el recurso suelo, lo cual enmarcado en:

1. el manejo adecuado de recipientes de plaguicidas, a través de la creación e implementación de un programa de manejo que demuestre evidencias tales como documentos escritos, donde se plasme la labor realizada, tiempos de recolección, tipo de tratamiento final, fechas de entrega del material y contrato con empresa recolectora; indicadores de su monitoreo, soportes de entrega a empresas con licencia ambiental para el manejo de los mismos o permisos para su disposición. Su medición se representa con uno (1) cuando exista este programa y con cero (0) en el caso contrario.

2. en la sustitución de plaguicidas, en el cual se considera a su vez la adopción de técnicas como el control biológico, donde se cuente con los soportes documentales de dicha labor. Este parámetro considera la representación en porcentaje del grado de aplicación de técnicas como el control biológico, relacionado con el tamaño del cultivo, pues se considera que el área de la empresa que se encuentra en producción, representa la zona con mayor susceptibilidad de ser contaminada con el uso de plaguicidas. De esta forma, se determina que entre mayor sea la cantidad de hectáreas en producción asociada a una política de uso de agroquímicos igual o superior al $50 \%$, mayor es la posibilidad de afectar el recurso. En este sentido, su medición corresponderá a: empresas con cultivos de menos de $10 \mathrm{Ha}$, pequeñas (1); entre 10 y $30 \mathrm{Ha}$, mediana (0.5); mayor a $30 \mathrm{Ha}$, grande (0).

En el caso en que la política empleada en la empresa no conlleve el uso de plaguicidas de ningún tipo, es decir, que posea un $100 \%$ de estrategias sustitutas, el valor de esta variable será siempre 1 , sin importar el tamaño del cultivo.

Cuando exista una proporción determinada entre el uso de plaguicidas y un sustituto de ellos, como el control biológico mencionado anteriormente, se plantea considerar el siguiente esquema: entre mayor sea la cantidad de hectáreas en producción, mayor es la cantidad de recurso conservado, cuando se aplican políticas de sustitutos de plaguicidas. En este sentido, cuando una empresa emplee un esquema de control biológico superior o igual al 60\% (y diferente del 100\%), su medición estará asociada al tamaño de la empresa, así: organizaciones con cultivos de menos de $10 \mathrm{Ha}$, pequeñas, (0.25); entre 10 y $30 \mathrm{Ha}$, mediana (0.5); y mayor a $30 \mathrm{Ha}$, grande (0.75). Como puede observarse en estas calificaciones, no se otorgan los valores de cero ni uno. El valor de uno, que corresponde a la máxima calificación posible del criterio, no se otorga bajo este esquema, porque aunque la proporción de sustancias químicas empleadas sea baja (menor al 40\%) sigue existiendo uso de ellas, situación que afecta negativamente el recurso suelo. En el caso del valor cero, mínima calificación posible, el criterio no lo considera, puesto que lo que se busca es incentivar a la empresa para que lleve a cabo disminuciones graduales del uso de sustancias químicas, objetivo que teniendo valores de cero no se lograría. Por esta razón, la calificación de este criterio inicia en 0.25 . 


\subsubsection{Relación empresa-mercado}

Este criterio plantea elementos que permitan evidenciar cómo a través del tiempo se genera un mejoramiento en la situación general de la organización, asociado a la inserción de su gestión ambiental. En este sentido, se considera:

- El tipo de mercado que atiende la empresa, ya sea interno o externo. En este caso, se favorecerían aquellas empresas que tengan una mayor proyección de exportaciones, dado que esto incrementaría el nivel económico de la compañía, posibilitando una mejora sustancial de todas sus características y se generaría un mayor aporte al mejoramiento de las condiciones nacionales. Su medición será de 1 en el caso en que se exporte la totalidad de la producción generada; 0.25 cuando sea netamente abastecimiento de mercado interno. Cuando haya representación de ventas en ambos mercados, se tendrán las siguientes bases: Si de la producción generada, se exporta $60 \%$ o más (0.75); si se exporta menos de este valor, la calificación dada es 0.35 .

- Otro elemento considerado en la relación empresa-mercado es la productividad, definida como el aumento en el número de unidades vendidas por la empresa año a año. Su medición se hará con respecto a rangos de variación, considerando un incremento mayor o igual al 15\% (1), entre 10\% y 15\% (0.75), entre $5 \%$ y $10 \%(0.5)$; entre $1 \%$ y $5 \%(0.25)$ y menor a $1 \%$ o decrecimiento (0).

- Por otra parte, el grado de penetración del mercado, también es considerado y tiene en cuenta elementos como: (a) la diversificación de mercados, (b) la diversificación de productos y (c) la estabilidad en el mercado. El primer elemento se refiere al ingreso a nuevos mercados, es decir, si inicialmente una empresa exporta a Estados Unidos, se esperaría que con la adopción de herramientas ambientales, se logre acceder también al mercado español, y así sucesivamente. Este elemento también considera la expansión de una empresa a diversos mercados ubicados en un mismo país. En este sentido, si la empresa logra acceder a nuevos mercados, tendría una calificación de uno (1) y en el caso contrario, de cero (0).

Ahora, la diversificación de productos vendidos, considera la capacidad de una empresa para vender en un período determinado de tiempo, diferentes productos en los mercados que atiende o que incursiona, esto significa, que si inicialmente la compañía A vende un producto $Y$, se esperaría que en 2 años, venda también el producto $Z$; en este caso tendría una calificación de uno (1) y cero en el caso contrario. Por último, el sub-criterio de estabilidad del mercado, tiene en cuenta la capacidad de una empresa para exportar consecutivamente sus productos en un período determinado. Su calificación varía de la siguiente manera: si la empresa logra exportar por un período consecutivo de 5 años o más (1), entre 3 y 5 años $(0,75)$; entre 1 y 3 años $(0,5)$ y menos de un año (0).

\subsubsection{Monitoreo de la calidad del recurso suelo}

Se define como la concentración del plaguicida encontrado en el suelo analizado, la cual, si supera el valor límite permisible estipulado tiene una calificación de cero (0) y en el caso contrario, un valor de uno (1). Este criterio también podría evaluarse teniendo en cuenta el porcentaje de superación del valor límite permisible (VLP), por ejemplo, si el dato hallado en el suelo supera en un 5\% el VLP, la calificación es 0.75 ; si lo supera entre 10\% y 20\% (0.35) y si es mayor al 20\% (0). Adicionalmente, para el cálculo de la subvención es necesario otorgar un peso específico para cada criterio, que permita ponderar el índice estandarizado y de ésta forma, obtener el valor del instrumento. En este sentido, se definió que los criterios características del plaguicida y gestión ambiental, tendría cada uno un peso de $30 \%$ sobre el total, dado que ambos representan el grado de contaminación o mejora ambiental que puede llegar a generar una empresa en sus actividades cotidianas, relacionadas con el recurso suelo.

Por su parte, los criterios relación empresa-mercado y calidad del suelo, poseen un peso cada uno de $20 \%$ sobre el total. El primer criterio se valoró de esta forma, puesto que es un elemento que permite representar el grado en que la inserción de la 
Tabla 4. Asignación de factores de ponderación y pesos de cada criterio ${ }^{15}$

\begin{tabular}{|c|c|c|c|c|c|c|c|}
\hline Criterio & & Sub-criterio & Índice estandarizado & $\begin{array}{l}\text { Peso } \\
\text { del } \\
\text { criterio }\end{array}$ & $\begin{array}{l}\text { Ponderación } \\
\text { (Wi) }\end{array}$ & \multicolumn{2}{|c|}{$\begin{array}{c}\text { Valor } \\
\text { máximo del } \\
\text { criterio }\end{array}$} \\
\hline \multirow{8}{*}{$\begin{array}{l}\text { Caracte- } \\
\text { rísticas del } \\
\text { plaguicida }\end{array}$} & \multirow{4}{*}{\multicolumn{2}{|c|}{ Toxicidad (T) }} & 0 , altamente tóxico & \multirow{8}{*}{$30 \%$} & \multirow{8}{*}{$\mathrm{CP}=\mathrm{T}+\mathrm{P}$} & \multirow{8}{*}{\multicolumn{2}{|c|}{2}} \\
\hline & & & 0,33, moderadamente tóxico & & & & \\
\hline & & & 0,66 , bajamente tóxico & & & & \\
\hline & & & 1, no tóxico & & & & \\
\hline & \multirow{4}{*}{\multicolumn{2}{|c|}{ Persistencia $(P)$}} & 0, muy persistente & & & & \\
\hline & & & 0,33, persistente & & & & \\
\hline & & & 0.66, moderadamente persistente & & & & \\
\hline & & & 1, no persistente & & & & \\
\hline \multirow{11}{*}{$\begin{array}{l}\text { Gestión } \\
\text { ambiental } \\
\text { empresarial }\end{array}$} & \multirow{2}{*}{\multicolumn{2}{|c|}{$\begin{array}{l}\text { Manejo adecuado de recipientes de plagui- } \\
\text { cidas (MP) }\end{array}$}} & 1, existencia de programa & \multirow{11}{*}{$30 \%$} & \multirow{11}{*}{$\begin{array}{c}\mathrm{GA}=\mathrm{MP}+ \\
\mathrm{SP}+\mathrm{FV}\end{array}$} & \multirow{11}{*}{3} & \multirow{11}{*}{2.75} \\
\hline & & & 0, no existencia de programa & & & & \\
\hline & \multirow{2}{*}{\multicolumn{2}{|c|}{ Flor verde y/o sellos verdes (FV) }} & 1, existencia de certificación & & & & \\
\hline & & & 0 , inexistencia de certificación & & & & \\
\hline & \multirow{7}{*}{$\begin{array}{l}\text { Sustitución } \\
\text { de plaguici- } \\
\text { das (SP) }\end{array}$} & \multirow{3}{*}{$\begin{array}{l}\text { Uso estricto de plaguicidas o } \\
\text { superior o igual a } 50 \% \text { (SP1) }\end{array}$} & $<10 \mathrm{Ha}, 0.35$ & & & & \\
\hline & & & Entre 10 y $30 \mathrm{Ha}, 0,25$ & & & & \\
\hline & & & $>30 \mathrm{Ha}, 0$ & & & & \\
\hline & & $\begin{array}{l}\text { Uso estricto de sustitutos } \\
\text { (control biológico) (SP2) }\end{array}$ & Cualquier tamaño del cultivo, 1 & & & & \\
\hline & & & $<10 \mathrm{Ha}, 0.55$ & & & & \\
\hline & & 60\% o mas de sustitutos & Entre 10 y $30 \mathrm{Ha}, 0,65$ & & & & \\
\hline & & & $>30 \mathrm{Ha}, 0.75$ & & & & \\
\hline \multirow{17}{*}{$\begin{array}{l}\text { Relación } \\
\text { empresa- } \\
\text { mercadeo }\end{array}$} & \multirow{4}{*}{$\begin{array}{l}\text { Mercado al } \\
\text { que atiende } \\
\text { (M) }\end{array}$} & $100 \%$ de producción se exporta & 1 & \multirow{17}{*}{$20 \%$} & \multirow{17}{*}{$\begin{array}{c}\text { REM = } \\
M+P r+D M+ \\
D P+E M\end{array}$} & \multirow{17}{*}{\multicolumn{2}{|c|}{5}} \\
\hline & & $\begin{array}{l}100 \% \text { de producción se co- } \\
\text { mercializa en mercado interno }\end{array}$ & 0.25 & & & & \\
\hline & & Abastecimiento & $\begin{array}{l}\text { si el } 60 \% \text { o más de la producción } \\
\text { se exporta, } 0.75\end{array}$ & & & & \\
\hline & & interno y externo & $\begin{array}{l}\text { Si se exporta menos del } 60 \% \text { de la } \\
\text { producción, } 0.35\end{array}$ & & & & \\
\hline & \multirow{5}{*}{\multicolumn{2}{|c|}{ Productividad (Pr) }} & 1, Incremento mayor o igual al $15 \%$ & & & & \\
\hline & & & 0,75 , crecimientoentreun $10 \%$ y $15 \%$ & & & & \\
\hline & & & 0.5 , entre $5 \%$ y $10 \%$ & & & & \\
\hline & & & 0.25, entre $1 \%$ y $5 \%$ & & & & \\
\hline & & & $\begin{array}{l}0 \text {, incremento menor a } 1 \% \text { o de- } \\
\text { crecimiento }\end{array}$ & & & & \\
\hline & \multirow{2}{*}{\multicolumn{2}{|c|}{ Diversificación de mercados (DM) }} & 1, si hay diversificación & & & & \\
\hline & & & 0, si no hay diversificación & & & & \\
\hline & \multirow{2}{*}{\multicolumn{2}{|c|}{ Diversificación de productos (DP) }} & 1, si hay diversificación & & & & \\
\hline & & & 0, si no hay diversificación & & & & \\
\hline & \multirow{4}{*}{\multicolumn{2}{|c|}{ Estabilidad en el mercado (EM) }} & $\begin{array}{l}\text { 1, si logra exportar por } 5 \text { años o } \\
\text { más de forma consecutiva }\end{array}$ & & & & \\
\hline & & & $\begin{array}{l}0.75 \text {, exportación consecutiva de } \\
3 \text { y } 5 \text { años }\end{array}$ & & & & \\
\hline & & & $\begin{array}{l}0.5 \text {, exportación consecutiva entre } \\
1 \text { y } 3 \text { años }\end{array}$ & & & & \\
\hline & & & 0, menos de 1 año exportando & & & & \\
\hline
\end{tabular}

15 Fuente: Elaboración propia. "Es importante resaltar que dado que en la actualidad no se cuenta con un establecimiento estándar de valores límites permisibles en el suelo, se tendrá en cuenta el procedimiento seguido en España y los datos proporcionados por la Universidad de Hertfordshire (2005), donde se presentan algunas características de los plaguicidas, que permitirán calcular dicho valor. 


\begin{tabular}{|c|c|c|c|c|c|c|}
\hline \multirow{5}{*}{$\begin{array}{l}\text { Calidad } \\
\text { del recurso } \\
\text { suelo }\end{array}$} & Concentración del plaquicida 1 & $\begin{array}{l}\text { 1, si no supera el valor límite per- } \\
\text { misible* }\end{array}$ & \multirow{5}{*}{$20 \%$} & \multirow{5}{*}{ CS } & \multirow{5}{*}{1} & \multirow{5}{*}{0.75} \\
\hline & concentracion der praguiciua I & $\begin{array}{l}0 \text {, si supera el valor límite permi- } \\
\text { sible }\end{array}$ & & & & \\
\hline & \multirow{3}{*}{ Concentración del plaguicida 2} & Dato supera en $5 \%$ el VLP, 0.75 & & & & \\
\hline & & $\begin{array}{l}\text { Dato supera entre } 10 \% \text { y } 20 \% \text { el } \\
\text { VLP, } 0.35\end{array}$ & & & & \\
\hline & & Dato supera en un $20 \%$ VLP, 0 & & & & \\
\hline
\end{tabular}

Tabla 5. Valor del factor $f$ requerido para el cálculo de la Tarifa Mínima16

\begin{tabular}{|c|c|c|}
\hline Factor & Monto (precios de 1997) & Monto (precios de 2009) \\
\hline $\mathbf{f}($ Us) & 56.25 & 81.10 \\
\hline $\mathbf{f}(\$)$ & 113564.81 & 163742.83 \\
\hline
\end{tabular}

variable ambiental en el proceso de toma de decisiones de una empresa y en su manejo en general, logra mejorar sus condiciones económicas. La calidad del suelo a su vez, fue valorada con este peso, debido a que es un aspecto importante y representativo del estado del recurso suelo y su grado de afectación o contaminación. De esta manera, es importante resaltar que sumando el peso de aquellos criterios que responden al manejo del recurso suelo por parte de las empresas, se obtiene un valor del $80 \%$ del total del peso de la subvención; dato que permite garantizar que el instrumento económico conserve como base la relación de la administración general de la empresa, con la temática ambiental, específicamente, aquella relacionada con el suelo.

Teniendo en cuenta la información planteada para cada criterio, la Tabla 4, presenta un resumen donde se asignan los factores de ponderación y la estandarización de cada uno de ellos, de tal manera que puedan ser comparados entre sí.

\subsection{Cálculo de la subvención a partir de la ponderación de criterios}

Ahora, el monto de la subvención (MS) a otorgar a una empresa se calcula mediante las siguientes fórmulas:

\footnotetext{
16 Fuente: Cálculos propios.
}

$S=W_{C P} C P+W_{G A} G A+W_{R E M} R E M+W_{C S} C S$

$S$, se refiere al valor ponderado de todos los criterios.

$$
M S=S^{*} T m
$$

Donde Tm corresponde a la tarifa mínima para conceder la subvención. Éste dato se determina a partir del valor de los beneficios generados en el uso de técnicas como la biorremediación natural, en la cual los organismos presentes en el suelo se encargan de transformar aquellas sustancias ajenas a él. En este sentido, se parte del valor del beneficio económico total estimado por Pimentel \& Greiner (1997) de 22.5 billones de dólares por año en 400 millones de hectáreas a precios de 1997, que corresponde al área promedio de terreno agrícola en Estados Unidos. De esta manera, la tarifa mínima sería:

$$
T m=f^{*} \text { Área } a_{-} \text {empresa }
$$

Donde $f$ corresponde a una constante obtenida al dividir 22.5 billones de dólares entre 400 millones de Ha, actualizado a valores del año 2009, es decir, 163742.25 dólares/Ha. 
Es importante resaltar entonces que el valor de la Tarifa Mínima se calcula teniendo como base fundamental que la subvención busca dar un incentivo al empresario, de tal manera que con ésta tarifa se logre reflejar el valor que el Estado ahorraría si las organizaciones realizaran una gestión ambiental adecuada para el recurso suelo y de ésta forma, dicho monto se trasladaría al empresario, como reconocimiento a su labor. La Tabla 5 presenta el valor del factor $\mathrm{f}$ en dólares y pesos colombianos.

Ahora bien, los montos de la subvención a otorgar en cada empresa, deben estar asociados a unas metas de reducción de la contaminación del suelo generadas por el uso de sustancias como los plaguicidas, ya que, puede presentarse el caso de encontrar empresas con bajas calificaciones en los criterios ambientales, situación que conllevaría a que ésta se comprometa a realizar procesos de mejoramiento en su gestión ambiental. De igual forma, aquellas organizaciones que obtengan altos valores de la subvención, también deben comprometerse a continuar con el manejo ambiental que llevan hasta el momento, con miras a alcanzar la máxima subvención posible.

En este sentido, la meta asociada a la subvención tendría en cuenta un período de cumplimiento de dos años, sin embargo, el monto otorgado a una empresa se entregaría anualmente y estaría asociado con el grado de cumplimiento de dichas metas. Por consiguiente, se debe garantizar porcentajes de disminución en el grado de contaminación del recurso suelo asociado a la implementación de programas de mejoramiento ambiental, según las características de la empresa y la concertación entre sus directivos y los representantes del Estado, donde en general, se plantea que para el año 1 se tenga un cumplimiento del $60 \%$ de los programas convenidos y en el año 2 , se logre el $40 \%$ restante. Del grado de cumplimiento de estos programas depende la posibilidad o no que tiene una empresa para adquirir de nuevo la subvención y aumentar el valor de su monto, cuando aún no haya alcanzado su máximo valor.

\subsection{Establecimiento de un fondo ambiental como soporte económico a la subvención}

Como se mencionó anteriormente, el fondo ambiental tiene como propósito sostener el instrumento de la subvención económica que sería concedida a las empresas con el compromiso de revertir su grado de contaminación del recurso suelo, razón por la cual requiere diversas fuentes de financiación.

En este sentido, los recursos necesarios para la subvención se recogerían a través de un impuesto ambiental que des-estimule el uso de plaguicidas, además de acceder a créditos con el Banco Interamericano de Desarrollo o el Banco Mundial, asociar recursos de las Corporaciones Autónomas Regionales a la implementación de instrumentos económicos; acceder a programas de apoyo internacional para conservación de bosques, microcuencas y ecosistemas en general. Igualmente, es importante mencionar que el instrumento de la subvención será aplicado por un período finito de tiempo en el cual se alcance el nivel deseado de disminución en el uso de plaguicidas.

\section{Conclusiones}

Los recursos naturales son altamente importantes para el desarrollo de las actividades cotidianas del ser humano, pues de una u otra forma, intervienen en sus relaciones y median la producción de diversos satisfactores sociales que permiten generar una mejora en la calidad de vida de las personas. En este sentido y haciendo énfasis en el recurso suelo, puede decirse que existe una relación directa entre las actividades económicas que desempeña el ser humano y el recurso natural como tal, pues de éste se obtiene un conjunto de materiales e insumos que son empleados en los procesos productivos de las organizaciones y que la ayudan a mantenerse a través del tiempo, es decir, a permanecer en un nivel competitivo.

Sin embargo, el uso intensivo e indiscriminado de los recursos naturales, específicamente del suelo, está generando un fuerte impacto ambiental negativo en 
el recurso, de tal forma que si no se propende por su protección y conservación, puede llegarse a perder sus características y por ende su capacidad para ser empleado dentro de otros procesos productivos posteriores o como soporte para actividades de ocio y recreo, entre otras. Por consiguiente, la inserción de la gestión ambiental en las organizaciones se convierte en un elemento preponderante para su supervivencia.

Por su parte, los instrumentos económicos ambientales como herramientas de incorporación de gestión ambiental en las empresas pueden llegar a ser un elemento relevante para la estructura general administrativa de una organización, pues la incorporación de ésta gestión promueve no sólo el aporte organizacional hacia el medio ambiente, sino que también incentiva el mejoramiento económico de su actividad, en tanto se reconoce su competitividad y responsabilidad social, como elementos que pueden posibilitar el ingreso a nuevos mercados y lograr un mayor y mejor posicionamiento dentro de estos.

Es fundamental mencionar que la creación de un instrumento económico ambiental que considere el manejo adecuado de los recursos naturales, para este caso, del suelo, asociado al uso de plaguicidas; debe incorporar variables administrativas y económicas que permitan generar un reconocimiento a las organizaciones por la labor realizada en todas sus dependencias y campos, puesto que es el correcto acoplamiento de cada uno de los estamentos de una empresa, lo que le permitirá incorporar el mejoramiento continuo de sus procesos y el aumento de su productividad y rentabilidad, a través del desarrollo sostenible, es decir, promoviendo al máximo el equilibrio entre los componentes social, económico y ambiental de una organización.

Adicionalmente, es importante resaltar que los instrumentos económicos son herramientas eficientes y eficaces para el control y la posible prevención de fenómenos de contaminación, en tanto permiten generar acciones costo efectivas y presentan una mayor flexibilidad que las herramientas de comando y control, pues permiten generar desarrollo al tiempo que se promueven prácticas amigables con el medio ambiente como la compra de tecnologías limpias y la incorporación de buenas prácticas ambientales dentro de una organización.

Ahora, el establecimiento de valores económicos de los servicios ambientales de un recurso natural permite rescatar la importancia, en términos de orden de magnitud, que dichos servicios representan frente a cada una de las actividades que desarrolla el ser humano y en los beneficios que le genera. De esta manera, es importante realizar este tipo de análisis con el fin de determinar el valor económico de los servicios ofrecidos por un recurso, al tiempo que se establece el valor de su posible pérdida generada por fenómenos antrópicos de contaminación.

Específicamente, en el caso de estudio, el valor presente neto de los servicios en conjunto del ecosistema Tierra de cultivos en 50 Hectáreas de terreno, genera un valor en pesos colombianos de doscientos cuarenta y cuatro mil millones novecientos noventa y siete mil quinientos cuarenta y cinco $(\$ 244,997,045.36)$. Por su parte 50 hectáreas del ecosistema Bosques, en diez años representaría un valor económico en pesos colombianos de mil treinta y ocho millones quinientos setenta y cuatro mil cuatrocientos treinta y uno (\$1.038.574.431,41). Es importante mencionar que la integralidad del esquema de la subvención, plantearía entonces la inserción de estos valores en el establecimiento de la tarifa mínima empleada en el cálculo del monto de la subvención, dado que estos representan el monto que el Estado ahorraría si las organizaciones realizaran una correcta gestión del recurso suelo.

Es esencial plantear que para realizar una implementación rigurosa de la subvención establecida es necesario llevar a cabo un conjunto de pasos que en forma sucesiva, ayudarían a obtener resultados más confiables sobre la gestión ambiental enfatizada en el recurso suelo, realizada por una organización. En este sentido, es importante tener en cuenta las siguientes directrices:

- Determinación de procedimientos claros y específicos para la caracterización de los suelos contaminados. 
- Determinación de técnicas de muestreo para dichos sitios, de tal manera que se logre la estandarización de este procedimiento.

- Establecimiento de metodologías de extracción de contaminantes y análisis de los mismos.

- Determinación de valores límites permisibles generales y metodología de cálculo de niveles específicos de contaminación en un sitio que considere: el ordenamiento del territorio, las características del sitio, la evaluación del riesgo al ambiente, los ecosistemas y la salud humana; dado que éste parámetro aun no se ha reglamentado en Colombia.

- Metodologías de evaluación del riesgo de los sitios contaminados.

- Selección de tecnologías de remediación.

- Alcances y limitaciones de las tecnologías de remediación.

- Determinación del valor económico de los servicios ambientales que genera el recurso natural a analizar.

- Costos de tratamiento de suelos.

En síntesis, puede decirse que en el recurso suelo es fundamental crear una reglamentación que a partir de un análisis detallado de su problemática, pueda promover su cuidado y protección, pues aunque en la legislación ambiental colombiana se plantea la necesidad de realizar dichas prácticas, hasta la fecha no se ha logrado una intervención real y total por parte del Estado.

Igualmente, debe mencionarse que la creación de un instrumento económico como la subvención requiere de la existencia de un fondo ambiental que permita su financiación, para lo cual es necesario recurrir a diversas estrategias de generación de fondos como los impuestos ambientales. No obstante, es fundamental aclarar que la existencia tanto de la subvención, como del fondo es finita, puesto que a medida que disminuya el uso de sustancias químicas como los plaguicidas, se estará dando cumplimiento al objetivo central del instrumento el cual es disminuir la contaminación generada por el uso de agroquímicos a la vez que se incentiva a las organizaciones a incorporar procesos de gestión ambiental.
Haciendo énfasis en el fondo ambiental requerido para implementar el instrumento de la subvención, puede decirse que es necesario realizar un estudio minucioso que permita determinar el tipo de entidades susceptibles de aportar recursos para el sostenimiento del fondo, de tal manera que con ayuda de la legislación ambiental existente en el país y la internacional, se promueva la selección específica de fuentes de financiación regionales, nacionales e internacionales.

Así mismo, se expone que el cálculo de la tarifa mínima empleada en la subvención es una aproximación o indicativo del valor que debe considerarse en este caso, pues no se cuenta con la información necesaria para determinar su monto real. En este sentido, sería necesario iniciar un diagnóstico sobre el grado de contaminación del recurso suelo en Colombia, para poder realizar un estudio detallado de los costos de remediación de dichos suelos. De esta manera, se resalta que esta investigación se especificó en la generación de directrices y el diseño de instrumentos económicos que permitan minimizar los impactos ambientales negativos presentes en el suelo y analiza la variación en el valor del subsidio, según el grado de manejo ambiental y administrativo, sin embargo el monto generado es un indicativo y no un valor riguroso, puesto que la metodología de transferencia de beneficios no refleja el costo real del mejoramiento del suelo en Colombia, por lo tanto, es necesario realizar investigaciones futuras que permitan definir dichos valores.

Así, la aplicación del instrumento creado es un paso posterior que debe realizarse con el fin de conocer los diferentes escenarios que podrían presentarse en empresas que cuenten con diferentes grados de gestión ambiental y empresarial. Ahora, es fundamental plantear también la necesidad de fortalecer la regulación ambiental existente en Colombia, de tal manera que sea más rigurosa y cumpla con su objetivo de preservar los recursos naturales, a través de la disminución de impactos ambientales negativos en el suelo. Esta situación puede generarse a partir del fortalecimiento de la capacidad institucional, considerando recursos económicos y humanos, elementos administrativos, infraestructura, entre 
otros aspectos de relevancia necesarios para la determinación de proyectos de esta índole.

Finalmente, se insiste que un trabajo necesario posterior a este estudio consiste en el establecimiento de normas sociales a partir de la creación de acuerdos o resoluciones de implementación de instrumentos económicos a escala regional, que cuenten con la determinación minuciosa y rigurosa de los costos de descontaminación de suelos y de los recursos necesarios para la creación del fondo ambiental que permita sustentar la subvención ambiental establecida.

\section{Referencias}

Colombia, Decreto 1843 de 1991: Uso y manejo de plaguicidas. $36 \mathrm{pp}$.

Colombia. Constitución política de 1991.

Colombia. Decisión Andina 436 del Acuerdo de Cartagena. Disponible en <http://www.comunidadandina.org/normativa/ res/R843sg.htm > [Fecha de consulta: Junio de 2008]

Colombia. Decreto 1220 de 2005: Licencias ambientales. 12 pp.

Colombia. Decreto 1443 de 2004: Residuos de plaguicidas. 19 pp.

Colombia. Decreto 358 de 2002: Importación de los plaguicidas o sus materias primas este excluida del impuesto sobre las ventas. $20 \mathrm{pp}$

Colombia. Decreto Ley 2811 de 1974: Código de los recursos naturales renovables de Colombia. $250 \mathrm{pp}$

Colombia. Estatuto Tributario. Disponible en <http://www.estatutotributario.com/procesa1.php?texto $=424>[$ Fecha de consulta: Agosto de 2008]

Colombia. Ley 768 de 2002: Corporaciones autónomas regionales, las de desarrollo sostenible, los grandes centros urbanos y las autoridades ambientales.

Colombia. Ley 99 de 1993: Sistema Nacional Ambiental (SINA) y el Ministerio de Medio Ambiente y se dictan otras disposiciones en materia ambiental.

Colombia. Ley $9^{a}$ de 1979, por medio de la cual se reglamenta el código sanitario nacional.

Colombia. Resolución 209 de 1978: Restricciones, prohibiciones y suspensión de registros de plaguicidas de uso agrícola en Colombia.

Colombia. Resolución 447 de 1974: Uso de plaguicidas organoclorados en el cultivo del tabaco y cafeto, respectivamente.

Cornare (2005). Oriente Antioqueño: potencia ambiental y ecoturística. Revista El Reto. No 56. $21-27$ pp.

Correa, F. (1999). Valoración Económica de Servicios Ambientales en el Valle de Aburrá. Revista Semestre Económico. No 9. $107-130$ pp. Universidad de Medellín.

Correa, F. (2006). La Tasa Social de Descuento y el Medio Ambiente. Revista Lecturas de Economía. № 64.96 - 116 pp.

Costanza, R., et al. (1997). The Value of the World's Ecosystem Services and Natural Capital. Ecological economics. Vol 25, $N^{\circ} 13-15 \mathrm{pp}$.

DICCIONARIO DE LA REAL ACADEMIA DE LA LENGUA - DRAL (2005). Edición número 23.
Dorronsoro, C. (2007). Edafologíay Química Agrícola. Universidad de Granada. Disponible en: <http://edafologia.ugr.es/ conta/tema10/import.htm> [Fecha de consulta: Junio de 2008].

Edwards, G. (2002). La tasa social de descuento en proyectos de largo plazo. Revista Documentos de trabajo, № 231, Noviembre, Instituto de Economía, Pontificia Universidad Católica de Chile. 80 pp.

EPA (2009). Acute toxicity class (formulation). Disponible en: $<$ http://sitem.herts.ac.uk/aeru/footprint/en/docs/PPDB Background_and_Support.pdf> [Fecha de consulta: Mayo de 2009]

García, L. (2006). Instrumentos económicos en Colombia: Una visión general. Montería, Colombia. Disponible en: < http://instrumentoseconomicos.zoomblog.com/archivo/2006/12/16/ instrumentos-economicos-en-Colombia--U.html> [Fecha de consulta: mayo 13 de 2009].

Holdridge, L.R. (1967). Life zone ecology: Tropical Science Center, San José, Costa Rica.

León, N. (2006). Mecanismos para la Regulación Ambiental. Bogotá, D.C: Universidad Nacional de Colombia, Sede Bogotá; Facultad de Ciencias Económicas. Primera edición. 119 pp.

Miranda, J. J. (2001). Gestión de Proyectos. Identificación - formulación, Evaluación financiera - económica - social - ambiental. Cuarta edición. 101 pp.

Montes, C. \& García, M. (2005). Capítulo: Plaguicidas catalogados como contaminantes orgánicos persistentes (COP) y su reglamentación jurídica. Libro: Lecturas sobre derecho del medio ambiente. Tomo VI. Universidad Externado de Colombia. Colombia. $229-256 \mathrm{pp}$.

Osorio, J. D. (2006). El método de transferencia de beneficios para la valoración económica de servicios ambientales: Estado del arte y aplicaciones. Revista Semestre Económico, Volumen 9, No 18. Universidad de Medellín. 107 - 124 pp.

Pimentel, D. \& Greiner, A. (1997). Environmental and socio-economics impacts of pesticida use. 51 - 78 pp. in Pimentel D, ed. Techniques for reducing pesticide use: environmental an economics benefits. Chichester (UK): Jhon Wiley Sons.

Porter, M. \& Van der Linde, C. (1995). Toward a new conception of the environment-competitiveness relationship. Journal of Economic Perspectives, Volumen 9, N0 4, 97-119 pp.

Riera, P., García, D., Kriström, B., \& Runar, B. (2005). Manual de economía ambiental y de los recursos naturales. Madrid, Thomson Editores. 355 pp.

Rosenberger, R. \& Loomis, J. (2003). Benefit Transfer, Chapter 12. A primer on nonmarket valuation, Editado por Patricia $A$ Champ y Kevin J Boyle, New York, Thomas C Brwn-Business and Economics. 107 pp.

Sanclemente, G. (2000). Bases legales para el diseño y aplicación efectiva de cargos por contaminación en países en desarrollo. Curso cargos por contaminación. World Bank Institute, The Andean Center for Economics in the Environment. $1-10 \mathrm{pp}$.

University of Hertfordshire (2005). Agriculture and environment research unit. Pesticide Properties Database (PPDB). Disponible en: <http://sitem.herts.ac.uk/aeru/projects/ppdb/index.htm> [Fecha de consulta: Julio de 2008]. 